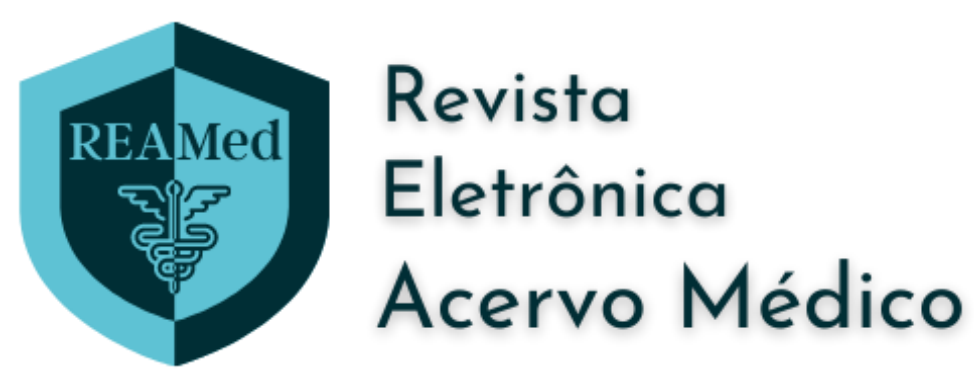

\title{
Estudo Epidemiológico sobre Hepatite na Região Nordeste entre 2010 a 2018 através de dados do DATASUS
}

\author{
Epidemiological Study on Hepatitis in the Northeast Region between 2010 to 2018 using \\ data from DATASUS
}

Estudio Epidemiológico sobre Hepatitis en la Región Noreste entre 2010 y 2018 utilizando datos de DATASUS

Andréia Raniely de Almeida Sousa ${ }^{1 *}$, Adrissa Alana Carneiro Alves², Ana Luiza Mamede ${ }^{3}$, Carolyne Nobre Alencar Teixeira Maciel ${ }^{1}$, Daniela Maria Souto Marques ${ }^{4}$, Giovanna Galvão Talassi ${ }^{5}$, Luana Silva Pinheiro ${ }^{1}$, Márcia Silva Rios ${ }^{1}$, Paula Pimentel Maia de Melo ${ }^{4}$, Ariany de Assis Moura ${ }^{6}$.

\section{RESUMO}

Objetivo: Descrever o número de contaminação pela hepatite na Região do Nordeste, no período de 2010 a 2018, por meio dos dados do DATASUS. Métodos: Estudo de caráter epidemiológico descritivo em que dados foram retirados do sistema TABNET, disponibilizados pelo DATASUS, com acesso em 5 , 9 e 15 de novembro de 2021. A população do estudo foram todos os casos de hepatite confirmados na Região Nordeste. Os dados foram coletados por meio de tabelas organizadas no programa Excel (versão 2010) para consolidação da informação e, utilizou-se do programa Canva para confecção de gráficos. Resultados: $A$ região nordeste apresenta maior número de infecções com os vírus $\mathrm{B}$ e $\mathrm{C}$ da hepatite, no entanto, o vírus $\mathrm{A}$ tem maior relevância nacional, pois a região é a segunda com maior casos. Reparou-se na precariedade de saneamento básico da região, bem como de medidas de prevenção contra a transmissão sexual. Outro dado crítico foi a falta de importância com o preenchimento das fichas de notificação, obtendo dados não completos sobre a hepatite. Conclusão: Conclui-se a necessidade de vigilância epidemiológica, necessidade de avaliação periódica da qualidade dos dados e aplicação eficaz das políticas públicas.

Palavras-chave: Hepatites, Região nordeste, Transmissão.

\footnotetext{
1 Universidade Christus (UNICHRISTUS), Fortaleza - CE.

*E-mail: andreia.raniely@hotmail.com

2 Faculdade Atenas (UNIATENAS), Sete Lagoas - MG.

3 Universidade de Mogi das Cruzes (UMC), Mogi das Cruzes - SP.

4 Faculdade Atenas (UNIATENAS), Passos - MG.

${ }^{5}$ Universidade Nove de Julho (UNINOVE), Guarulhos - SP.

${ }^{6}$ Universidade de Fortaleza (UNIFOR), Fortaleza - CE.
} 


\begin{abstract}
Objective: To describe the number of hepatitis infections in the Northeast Region, from 2010 to 2018, using data from DATASUS. Methods: Descriptive epidemiological study in which data were taken from the TABNET system, made available by DATASUS, with access on November 5, 9 and 15, 2021. The study population consisted of all conf irmed hepatitis cases in the Northeast Region. Data was collected through tables organized in the Excel program (version 2010) to consolidate the information and the Canva program was used to make graphs. Results: The northeast region has the highest number of infections with hepatitis $B$ and $C$ viruses, however, virus $A$ has greater national relevance, as the region is the second with the highest cases. It was noted the precariousness of basic sanitation in the region, as well as measures to prevent sexual transmission. Another critical fact was the lack of importance in completing the notification forms, obtaining incomplete data on hepatitis. Conclusion: It concludes the need for epidemiological surveillance, the need for periodic assessment of data quality and effective application of public policies.
\end{abstract}

Key words: Hepatitis, Northeast region, Transmission.

\title{
RESUMEN
}

Objetivo: Describir el número de infecciones por hepatitis en la Región Nordeste, de 2010 a 2018, utilizando datos de DATASUS. Métodos: Estudio epidemiológico descriptivo en el que se tomaron datos del sistema TABNET, puesto a disposición por DATASUS, con acceso los días 5, 9 y 15 de noviembre de 2021. La población de estudio estuvo constituida por todos los casos confirmados de hepatitis en la región. Los datos se recolectaron a través de tablas organizadas en el programa Excel (versión 2010) para consolidar la información y se utilizó el programa Canva para realizar las gráficas. Resultados: La región noreste tiene el mayor número de infecciones por virus de hepatitis $\mathrm{B}$ y $\mathrm{C}$, sin embargo, el virus $\mathrm{A}$ tiene mayor relevancia nacional, ya que la región es la segunda con mayor número de casos. Se señaló la precariedad del saneamiento básico en la región, así como las medidas para prevenir la transmisión sexual. Otro hecho crítico fue la falta de importancia en completar los formularios de notificación, obteniendo datos incompletos sobre hepatitis. Conclusión: Se concluye la necesidad de vigilancia epidemiológica, la necesidad de evaluación periódica de la calidad de los datos y la aplicación efectiva de las políticas públicas.

Palabras clave: Hepatitis, Región nordeste, Transmisión.

\section{INTRODUÇÃO}

As Hepatites Virais (HV) são infecções sistêmicas com afinidade pelo tecido hepático e é um grande problema de saúde pública no Brasil e no mundo. Existem diversos tipos de vírus que podem causar hepatite, sendo classificados em tipo A, B, C, D e E. A doença costuma evoluir para a forma benigna, cursando geralmente com sintomas inespecíficos, como fadiga, anorexia, náuseas, diarréias e dor leve em hipocôndrio direito (fase pré-ictérica). Com o passar do tempo, pode evoluir para a fase ictérica, com aumento dos níveis séricos das bilirrubinas totais, aminotransferases, perda ponderal e dor à palpação profunda no hipocôndrio direito (BANDEIRA LLB, et al., 2017).

A infecção pelos vários tipos de vírus da hepatite é a principal causa de desenvolvimento da cirrose, doença hepática crônica e carcinoma hepatocelular. Estima-se que no período de 1999 a 2020 no Brasil, mais de 200.000 pessoas foram diagnosticadas com o vírus da hepatite $B$, e números semelhantes também foram verificados para o tipo $\mathrm{C}$. Por causa do grande número de contágios e agravos, o combate da hepatite é um dos objetivos de desenvolvimento sustentável da Organização das Nações Unidas (ONU) (SAÚDE SDV, 2021).

A hepatite viral é um grande problema de saúde pública para o mundo e representa a sétima doença que causa mais mortes, ultrapassando outras doenças inf ecciosas crônicas, como HIV, malária e tuberculose. De todos os subtipos virais que causa a hepatite, a maioria das mortes é atribuída ao vírus $\mathrm{B}$ e ao vírus $\mathrm{C}$ (MATICIC M e MONDELLI MU, 2020). 
O comportamento epidemiológico da hepatite está passando por grandes mudanças nos últimos anos, mas apresentam diferenças em relação aos tipos de agentes etiológicos. Vale ressaltar que o Brasil teve avanços significativos no que tange a prevenção e controle das HV. Dentre esses progressos, pode-se pontuar o desenvolvimento de testes rápidos, surgimento de vacinas, rastreamentos de indivíduos e eficácia na identificação dos agentes virais (FERREIRA CT e SILVEIRA TRD, 2004).

A HV é uma doença de notificação compulsória, sendo necessário manter uma qualidade das informações contidas nas fichas de cada paciente. A qualidade é analisada pela inconsistência entre duas variáveis complementares e pelo completo preenchimento de cada uma dessas variáveis, considerando os campos em branco e ignorado. Alguns estudos de revisão da qualidade das bases de dados do sistema de informação em saúde mostraram uma precariedade de trabalhos acerca dessa análise no Brasil, em especial na região nordeste, em que foram encontrados poucos artigos acerca a completitude dos dados do Sistema de Informação de Agravos de Notificação (SINAN) e nenhum sobre da consistência dos dados (CORDEIRO TMSC e JÚNIOR ADO, 2018).

Objetivou descrever o número de contaminação pelos vírus da hepatite na Região Nordeste entre 2010 a 2018 através dos dados do Departamento de Informática do Sistema Único de Saúde (DATASUS). Os objetivos específicos foram: Identificar o número de contaminação por ano, analisar o local de maior frequência de contaminação, identificar o número de infecção por estado da região, descrever, em porcentagem e em números cardinais, a quantidade de contágio por escolaridade, sexo, faixa etária e cor/raça, além do perfil do tipo de vírus mais predominante.

\section{MÉTODOS}

Trata-se de um estudo epidemiológico descritivo, em que dados foram obtidos por meio de consulta às bases de dados do sistema TABNET, disponibilizados pelo DATASUS, acessado em 5, 9 e 15 de novembro de 2021. A população do estudo foi constituída por todos os casos confirmados de contaminação pelo vírus da hepatite na Região Nordeste, considerando o período de estudo entre 2010 a 2018. Os dados foram coletados por meio de tabelas organizadas no programa Excel (versão 2010) para consolidação da informação e, utilizou-se do programa Canva para confecção dos gráficos. A análise estatística foi baseada em medidas de tendência central como média, moda, mediana e desvio padrão.

\section{RESULTADOS E DISCUSSÃO}

No período de 2010 a 2018 no Brasil houve em torno de 345.000 casos confirmados de hepatite. Só na região nordeste foram 41.209 infecções nesse intervalo, correspondendo a uma porcentagem em torno de $11,92 \%$ de todos os pacientes com essa doença no país. Apesar disso, a maior quantidade de casos se concentra na região sudeste, com 133.896 casos de hepatite. De todas as cinco regiões, o nordeste ocupa o quarto lugar no que tange ao número da população infectada, apresentando um certo avanço em relação às demais.

Em análise dos dados coletados da plataforma DATASUS, percebeu-se que o maior número de contágio pelos vírus da hepatite se concentrava no tipo B, com 33,9\%, e tipo C, com 32,3\% entre os anos de 2010 a 2018 (Gráfico 1). Esses números são facilmente explicados pelo mecanismo de transmissão dos dois tipo de vírus, uma vez que eles tem como via de contágio principal as relações sexuais, contato com fluidos humanos infectados e transfusões sanguíneas (MARQUES JVS, et al., 2019).

A principal medida preventiva contra a hepatite B é a vacinação, sendo disponível para toda a população em qualquer idade de forma gratuita pelo Sistema Único de Saúde (SUS). Apesar disso, a cobertura vacinal ainda é baixa nos adultos, principalmente para o sexo masculino, podendo ser uma justificativa para o volume de infecções pelo vírus, além do fato de que esse público também costuma ter práticas sexuais com muitos parceiros e sem proteção (ROCHA DFNDC, et al., 2018). Estima-se que no Brasil apenas $50 \%$ da população está devidamente vacinada para esse tipo (PAOLI J, et al., 2018). 
Nota-se ainda um número significativo de contágio pelo vírus tipo $\mathrm{A}$, uma vez que possui mecanismo de transmissão simples e fácil (fecal-oral) (Gráfico 1). Esse achado entra em consonância com os dados da Fundação Instituto Brasileiro de Geografia e Estatística sobre o acesso aos serviços de saneamento básico, pois é uma questão de grande desafio para a região nordeste, que se apresenta como abaixo da média nacional para abastecimento de água, coleta de lixo e esgoto (SILVA APD, et al., 2020).

Gráfico 1 - Casos confirmados por Classificação Etiológica na Região Nordeste do ano de 2010-2018.

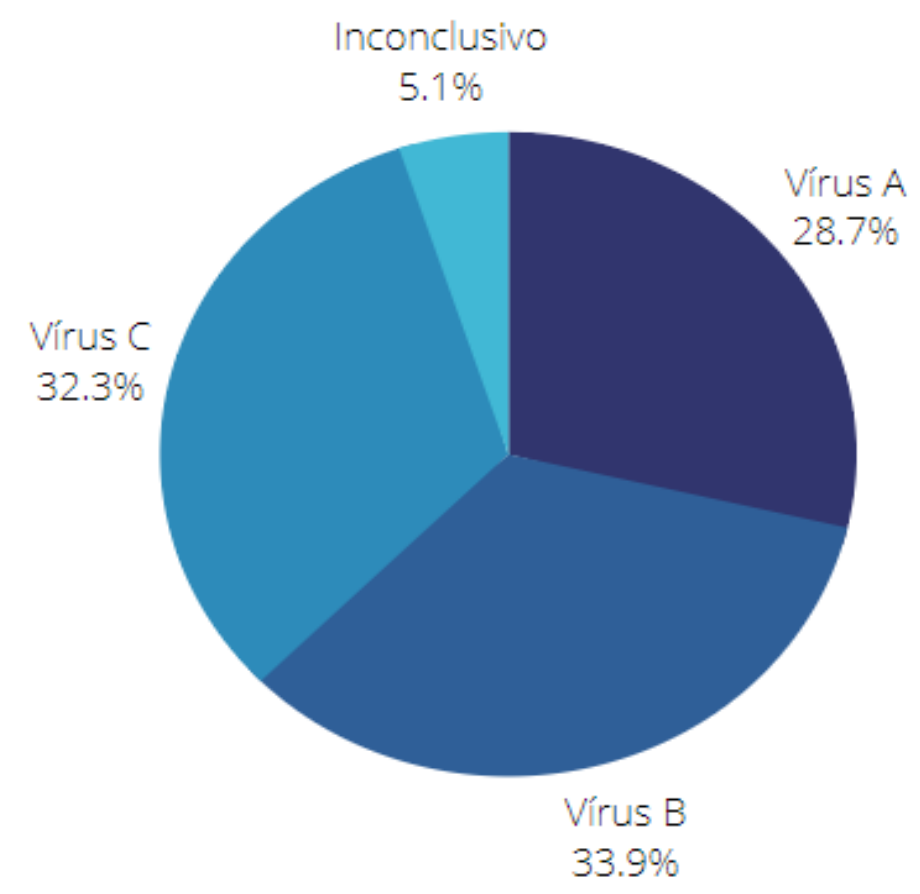

Fonte: SOUSA ARA, 2021; Dados extraídos do DATASUS.

Ainda sobre o vírus $A$, notou-se que a região nordeste é a segunda do país com maior número de casos, totalizando 11.577 pacientes com esse subtipo viral, ficando atrás apenas da região norte do Brasil, com 14,387 casos. Com isso, apesar do vírus $\mathrm{B}$ e $\mathrm{C}$ apresentarem maior número de pessoas contaminadas, 0 vírus $A$ tem maior importância se olharmos para nível nacional e em comparação às outras regiões. Assim, como possíveis medidas preventivas para a hepatite $A$, é imprescindível que a região nordeste adote investimentos em saneamento básico, higiene pessoal, vigilância sanitária e campanhas educativas, elevando sua média nacional em relação a esses parâmetros.

Além disso, percebe-se uma irrelevância de dados sobre os vírus $\mathrm{D}$, em que não aparece no Gráfico 1 devido a valores irrisórios. Uma provável explicação seria devido ao fato desse tipo de agente etiológico ser satélite do vírus $B$, além de também ter problemas na padronização de técnicas diagnósticas. Em última análise do gráfico, há uma parcela classificada como inconclusiva, demonstrando uma certa falha na qualidade dos dados nas fichas de notificação (STOCKDALE AJ, et al., 2020).

$\mathrm{Na}$ Tabela 1, percebe-se que a concentração de casos de hepatite é inconclusiva no que diz respeito à escolaridade. Sabe-se que a melhor forma de prevenção para a hepatite é a educação sexual e medidas de higiene, sendo, portanto, ações de fácil aplicabilidade em locais de ensino. Por conta disso, o nível de escolaridade não deveria ter a maior parte de casos sem uma devida classificação, para que houvesse uma maior análise crítica sobre o ensino do país. Além disso, caso o número de contaminação real fosse alto em pessoas com baixa escolaridade, seria uma excelente estratégia disseminar informações para esse público, diminuindo, assim, a quantidade de casos de hepatite da região. 
Tabela 1 - Casos confirmados por Escolaridade, Raça e Sexo na Região Nordeste do ano de 2010 a 2018

\begin{tabular}{lll}
\hline Variável & $\mathbf{N}$ & $\%$ \\
\hline Escolaridade & 13.418 & $32,56 \%$ \\
\hline Inconclusivo & 1.023 & $2,48 \%$ \\
Analf abeto & 4.453 & $10,8 \%$ \\
$1^{\circ}$ a $4^{\circ}$ série incompleta & 1.972 & $4,78 \%$ \\
$4^{\circ}$ série completa & 4.655 & $11,29 \%$ \\
$5^{\circ}$ a $8^{\circ}$ série incompleta & 1.874 & $4,54 \%$ \\
EF completo & 2.003 & $4,86 \%$ \\
EM incompleto & 5.316 & $12,9 \%$ \\
EM completo & 754 & $1,82 \%$ \\
Graduação incompleta & 1.311 & $3,18 \%$ \\
Graduação completa & 4.430 & $10,75 \%$ \\
Não se aplica & & \\
\hline Raça & 5.376 & $13,04 \%$ \\
Inconclusivo & 5.998 & $14,55 \%$ \\
Branca & 4.036 & $9,79 \%$ \\
Preta & 359 & $0,87 \%$ \\
Amarela & 25.145 & $61,01 \%$ \\
Parda & 295 & $0,71 \%$ \\
Indígena & & \\
\hline Sexo & 17 & $0,04 \%$ \\
\hline lgnorado & 21.911 & $53,17 \%$ \\
Masculino & 19.281 & $46,78 \%$ \\
Feminino & $\mathbf{4 1 . 2 0 9}$ & $\mathbf{1 0 0 \%}$ \\
\hline Total &
\end{tabular}

Fonte: SOUSA ARA, 2021; Dados extraídos do DATASUS

Analisando ainda a variável escolaridade, nota-se que o grupo correspondente a pessoas com ensino médio completo representa o segundo público com maior número de inf ecções, com 5.316 pessoas infectadas no período analisado. Esse número corresponde a $12,9 \%$ do total e demonstra uma contradição com o que era para ser esperado, uma vez que são pessoas com alto nível de escolaridade e acesso à informação, devendo adotar medidas de segurança contra as HV.

Entretanto, há alguns estudos que explicam esse número elevado em indivíduos com maior escolaridade. Uma das teorias propostas e analisadas é que esses casos são de infecções ocupacionais, ou seja, derivadas de acidentes de trabalhos, uma vez que quanto maior a escolaridade, maior é a complexidade das atividades laborais com maior exposição ao vírus. Assim, a maior parte dessa população são trabalhadores de saúde (CORDEIRO TMSC, et al., 2019).

Um artigo original mostrou que cerca de 1493 casos de HV foram por acidentes de trabalho entre 2007 e 2014. A região nordeste representa $11,9 \%$ desses casos, no entanto, os dados de notificação não estavam completos em relação a ocupação e a forma clínica da hepatite, apresentando um crescimento de dados incompletos no período estudado. Foi no estado de Pernambuco onde teve um maior índice de dados sem seu devido preenchimento. Dessa forma, percebe-se a grande importância da saúde do trabalhador para essa patologia, bem como a necessidade de dados qualificados para entender melhor o panorama de infecção do vírus (CORDEIRO TMSC e JÚNIOR ADO, 2018).

No que tange à raça, observou-se uma prevalência maior em pessoas pardas. Na variável sexo, há uma similaridade dos números, mas o sexo masculino apresenta maior número de contágios. Também, houve poucos casos preenchidos como inconclusivos, indicando ser uma variável notada nas informações de notificação.

Verificando a variável faixa etária, percebe-se que os indivíduos entre 40 a 59 são os mais suscetíveis para as HV, com 12.597 casos nesse intervalo de idade. Logo em seguida, são as pessoas com 20 a 39 anos que ocupam o segundo lugar da população contaminada com qualquer forma da hepatite. Essas duas faixas etárias correspondem justamente à atividade sexual ativa e, consequentemente, facilitando a transmissão das 
hepatites B e C pelo contato sexual. Dessa forma, concretiza, ainda mais, a necessidade de adotar medidas educativas sobre os métodos contraceptivos na região nordeste, bem como viabilizar o seu acesso em qualquer nível de atenção à saúde.

Entre o ano de 2014 e 2015 houve uma diminuição significativa (redução de 1977 casos) de HV no país, chegando a níveis mais baixos desde 2010. Com isso, pode-se caracterizar como um marco de ef etividade das políticas públicas contra essa doença. A partir de então, houve uma estabilidade com tendência para queda até o ano de 2018. O ápice ocorreu no ano de 2014 com 6.029 pacientes infectados (Gráfico 2).

Em relação ao tipo C, estimou-se que cerca de $0,31 \%$ da população em 2017, equivalente a 632.000 pessoas, possuíam o RNA positivo do vírus no organismo. No entanto, desde 2014, o Ministério da saúde forneceu acesso ao antivirais de ação direta sem interferon, conforme recomendação da Organização Mundial da Saúde (OMS), para o tratamento da hepatite C. Desde essa data, até 2017, cerca de 70.000 pessoas receberam a medicação, controlando ainda mais o segundo subtipo de vírus mais frequente na região nordeste (BENZAKEN AS, et al.,2019). Essa ação pode ser uma das justificativas da grande queda do número de casos entre 2014 e 2015 (Gráfico 2).

Gráfico 2 - Casos confirmados na Região Nordeste no ano de 2010-2018.

8 mil

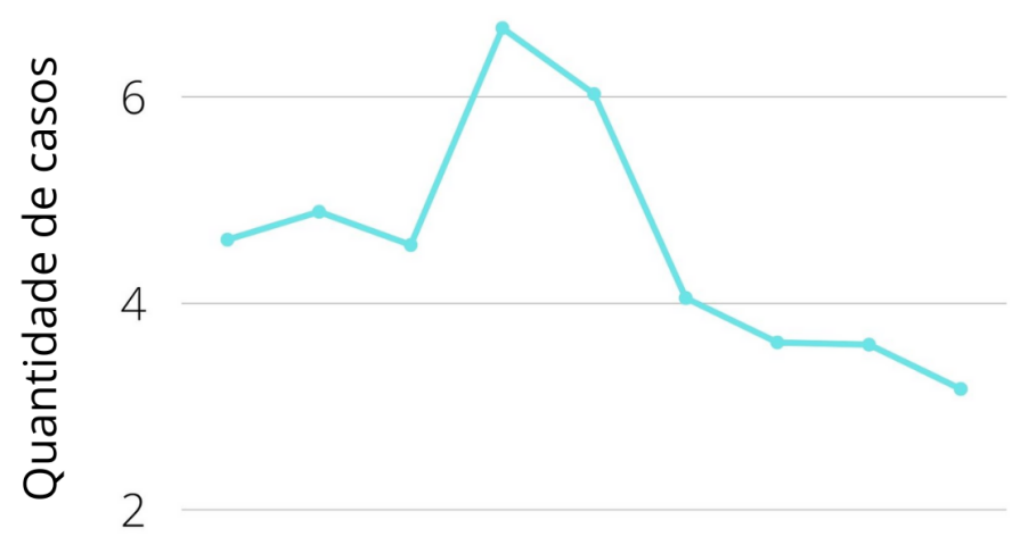

0

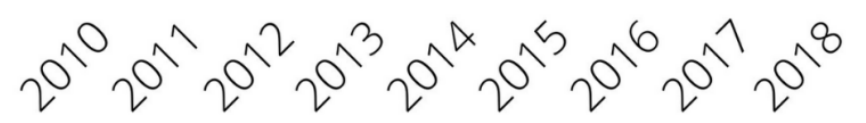

Ano

Fonte: SOUSA ARA, 2021; Dados extraídos do DATASUS.

Uma parte dessa queda pode ser devido à adesão do Ministério da Saúde em disponibilizar antivirais para portadores do vírus C nesse mesmo período. Apesar disso, desde 2002, o país reconheceu a grande importância dessa inf ecção e implementou o Programa Nacional de Hepatites Virais (PNHV), com os objetivos de promoção e prevenção da saúde, bem como assistência aos pacientes com hepatites virais, reforço da vigilância sanitária e epidemiológica, aconselhamento e testagem sorológica para as HV nos Centros de Testagem e Aconselhamento (CTA) e etc. O principal alvo é aumentar o diagnóstico e orientação, pois a maioria das pessoas desconhecem sua condição sorológica, agravando a cadeia de transmissão (SAÚDE SDVE, 2005). 
De acordo com um estudo feito para determinar o nível de conhecimento sobre as HV no Brasil, a região do nordeste teve um maior número de respostas erradas sobre a doença do que as demais regiões do país. Aproximadamente $90 \%$ do número de pessoas investigadas no nordeste responderam que não existia hepatite $\mathrm{D}$ ou $\mathrm{E}$ em um centro de saúde. Além disso, observou um maior número de dispersão de acertos na região. Em relação ao índice de acerto das perguntas aplicadas, apenas 39,4\% ficaram acima da média nas áreas de baixo recurso do nordeste. Concluiu-se a baixa percepção sobre essa doença, mostrando claramente a urgência de políticas educacionais no país, em especial nessa região, para combater o vírus (CRUZ HM, et al., 2018).

Analisando os estados da região nordeste, percebe-se que a Bahia foi o único local em que não houve evolução significativa durante todos esses anos, ocupando o topo do ranking de estado do nordeste com maior número de casos, ultrapassando a marca de 10.000 infecções acumuladas. O segundo estado com maior número de pacientes com hepatite foi o Maranhão. Apesar disso, ele apresenta uma diferença de, aproximadamente, $50 \%$ em relação à Bahia (Gráfico 3).

Gráfico 3 - Casos confirmados por Estados da Região Nordeste no ano de 2010 a 2018.

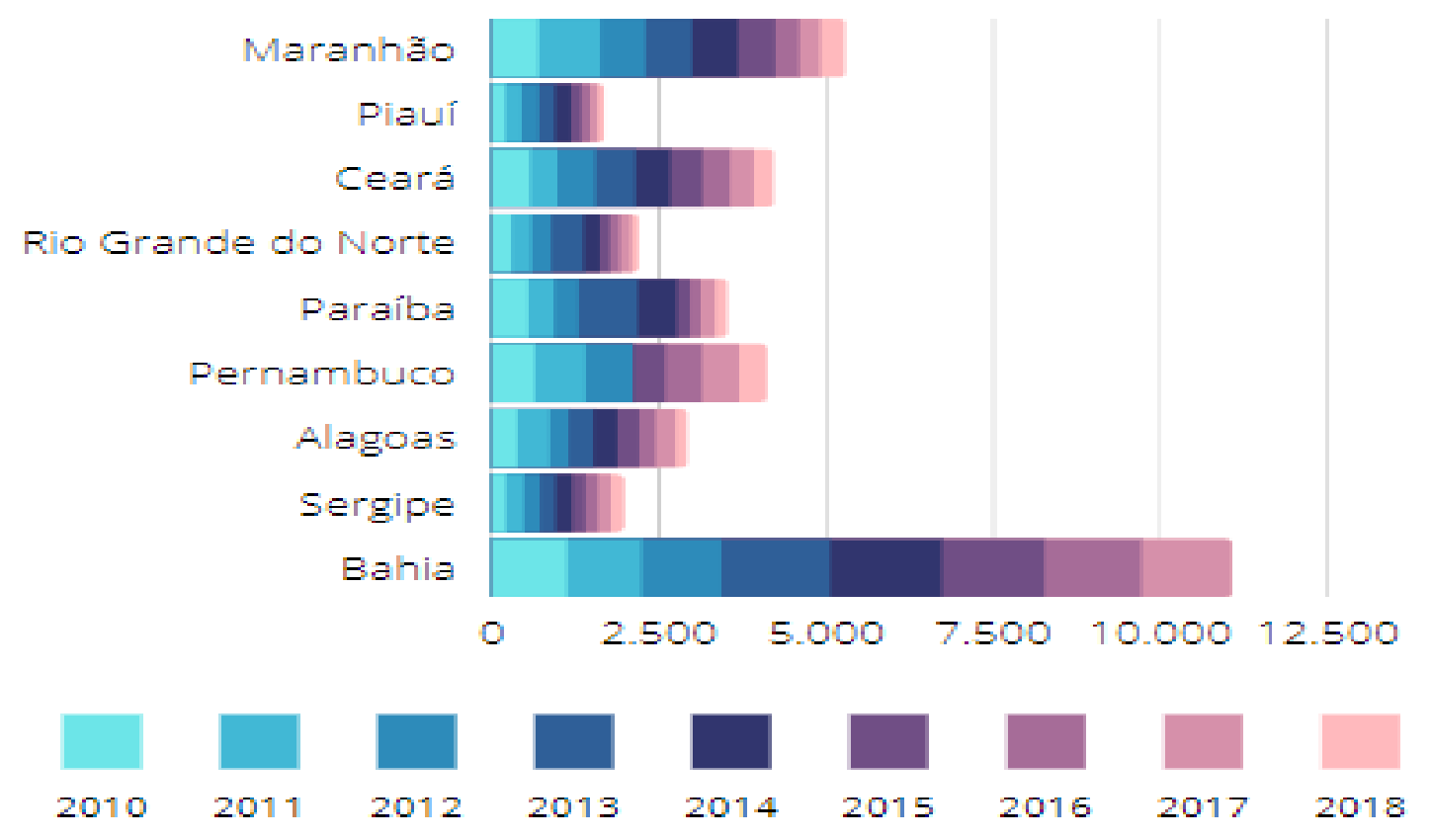

Fonte: SOUSA ARA, 2021; Dados extraídos do DATASUS.

Em estudo recente sobre a soroprevalência e distribuição espacial de hepatite $C$ na Bahia, encontrou que $1,3 \%$ da população analisada apresentava o anticorpo para o vírus C (anti-HCV), tendo, portanto, uma prevalência maior que a estimada $(0,94 \%)$ para as capitais da região nordeste. Ainda, percebeu que a média de idade com a infecção girava em torno dos 55 anos, devido ao diagnóstico laboratorial ter sido adotado apenas em 1989 e a obrigatoriedade dos testes de doadores de sangue apenas em 1993. Além disso, maioria era do sexo masculino, apesar da maioria da população do estudo ser composta por mulheres, podendo essa predominância refletir o uso de drogas intravenosas em áreas urbanas e rurais (PEREIRA FM, et al., 2021).

$\mathrm{Na}$ avaliação dos dados, notou-se que o estado da Bahia também era o estado que se sobressaia em quase todas as formas de contágio pela hepatite, se responsabilizando por $41,6 \%$ da transmissão sexual da região nordeste, $52 \%$ pela forma transfusional, $67,2 \%$ no contágio pelo uso de drogas injetáveis, além de liderar também a transmissão vertical, por acidente de trabalho, tratamento dentário e de pessoa pra pessoa. Ainda, foi no estado da Bahia em que teve mais informações sem preenchimento adequado sobre as formas de transmissão, sendo, portanto, o estado com maior volume de informações não qualificadas nas fichas de notificação. 


\section{CONCLUSÃO}

As Hepatites Virais são consideradas um grande problema de saúde pública no Brasil, além de serem classificadas como doenças de notificação compulsória. Sabe-se que existem diversos subtipos de vírus que podem causar essa patologia, mas indubitavelmente o tipo $A, B$ e $C$ são os que mais causam o grande volume de infecções verificadas a cada ano. Com esse estudo, conclui-se a grande necessidade de uma constante vigilância epidemiológica com as HV no país, bem como uma avaliação periódica da qualidade dos dados notificados, devendo os profissionais de saúde serem instruídos para valorizar essas informações. Ainda, notou-se para o volume de casos em indivíduos com alto nível de escolaridade na região nordeste, podendo direcionar para um possível problema de acidentes de trabalhos e evidenciando para que novos estudos sejam feitos com o intuito de elucidar essa questão. Por fim, ficou clara a importância de combate da doe nça no nordeste com aplicação eficaz das políticas públicas devido à carência informacional e ao número de infecções, apesar de não ser a principal região af etada pelas hepatites.

\section{REFERÊNCIAS}

1. BANDEIRA LLB, et al. Epidemiologia das hepatites virais por classificação etiológica. Rev. Soc. Bras. Clin. Med., 2017;16(4):227-231.

2. BENZAKEN AS, et al. Hepatitis $C$ disease burden and strategies for elimination by 2030 in Brazil. A mathematical modeling approach. The Brazilian Journal of Infectious Disease, 2019;23(3):182-190

3. CORDEIRO TMSC, JÚNIOR ADO. Qualidade dos dados das notificações de hepatites virais por acidentes de trabalho, Brasil. Rev. Bras. Epidemiol., 2018;21(1):1.

4. CORDEIRO TMSC, et al. Factors associated with occupational and non-occupational viral hepatitis infections in Brazil between 2007-2014. Ann. Hepatol., 2019; 18(5):751-756.

5. CRUZ HM, et al. Cross-sectional study to determine viral hepatitis knowledge in different urban populations in Brazil. World J. Hepatol., 2018; 10(11): 867-876.

6. FERREIRA CT, SILVEIRA TRD. Hepatites virais: aspectos da epidemiologia e da prevenção. Rev. Bras. Epidemiol., 2004; 7(4): 473-487.

7. MARQUES JVS, et al. Análise Sociodemográfica das Hepatites Virais no Estado do Ceará. Sanare, 2019;18(2):2633.

8. MATICIC M, MONDELLI MU. Elimination of viral hepatitis: where do we stand in the year 2020?. Clin. Microbiol. Infect., 2020; 26 (7):816-817.

9. PAOLI JD, et al. HBV epidemiology and genetic diversity in an area of high prevalence of hepatitis B in southern Brazil. Braz. J. Infect. Dis., 2018; 22(4):294-304.

10. PEREIRA FM, et al. Seroprevalence and Spatial Distribution of Hepatitis C Virus in Bahia, Brazil. Am J. Trop. Med. Hyg., 2021; 105(4): 991-998.

11. ROCHA DFNDC, et al. Epidemiology of HIV, syphilis, and hepatitis B and $C$ among manual cane cutters in low -income regions of Brazil. BMC Infect. Dis., 2018; 18(1):546.

12. SAÚDE SDV. Boletim Epidemiológico de Hepatites Virais: 2021 . Ministério da Saúde, 2021;1-80.

13. SAÚDE SDVE. Programa Nacional para a Prevenção e o Controle das Hepatites Virais: Manual de aconselhamento em Hepatites Virais.Ministério da Saúde, 2005;1:1-54.

14. SILVA APD, et al. Incidence of viral hepatitis in Brazil from 2009 to 2018: an epidemiological study of confirmed cases of viral hepatitis. Rev. Soc. Bras. Med. Trop., 2020;54(1):1.

15. STOCKDALE AJ, et al. The global prevalence of hepatitis $D$ virus infection: Systematic review and meta-analysis. J. Hepatol., 2020; 73(3):523-532. 